Zola before the Rougon-Macquart 


\section{UNIVERSITY OF TORONTO ROMANCE SERIES}

1. Guido Cavalcanti's Theory of Love, by J. E. SHAw

2. Aspects of Racinian Tragedy, by JoHN C. LAPP

3. The Idea of Decadence in French Literature, 1830-1900, by A. B. CARTER

4. Le Roman de Renart dans la littérature française et dans les littératures étrangères au moyen âge, par JoHN FLINN

5. Henry Céard : Idéaliste détrompé, par RONALD FRAZEB

6. La Chronique de Robert de Clari : Etude de la langue et du style, par P. F. DEMBOWSKI

7. Zola before the Rougon-Macquart, by JOHN C. LAPP 



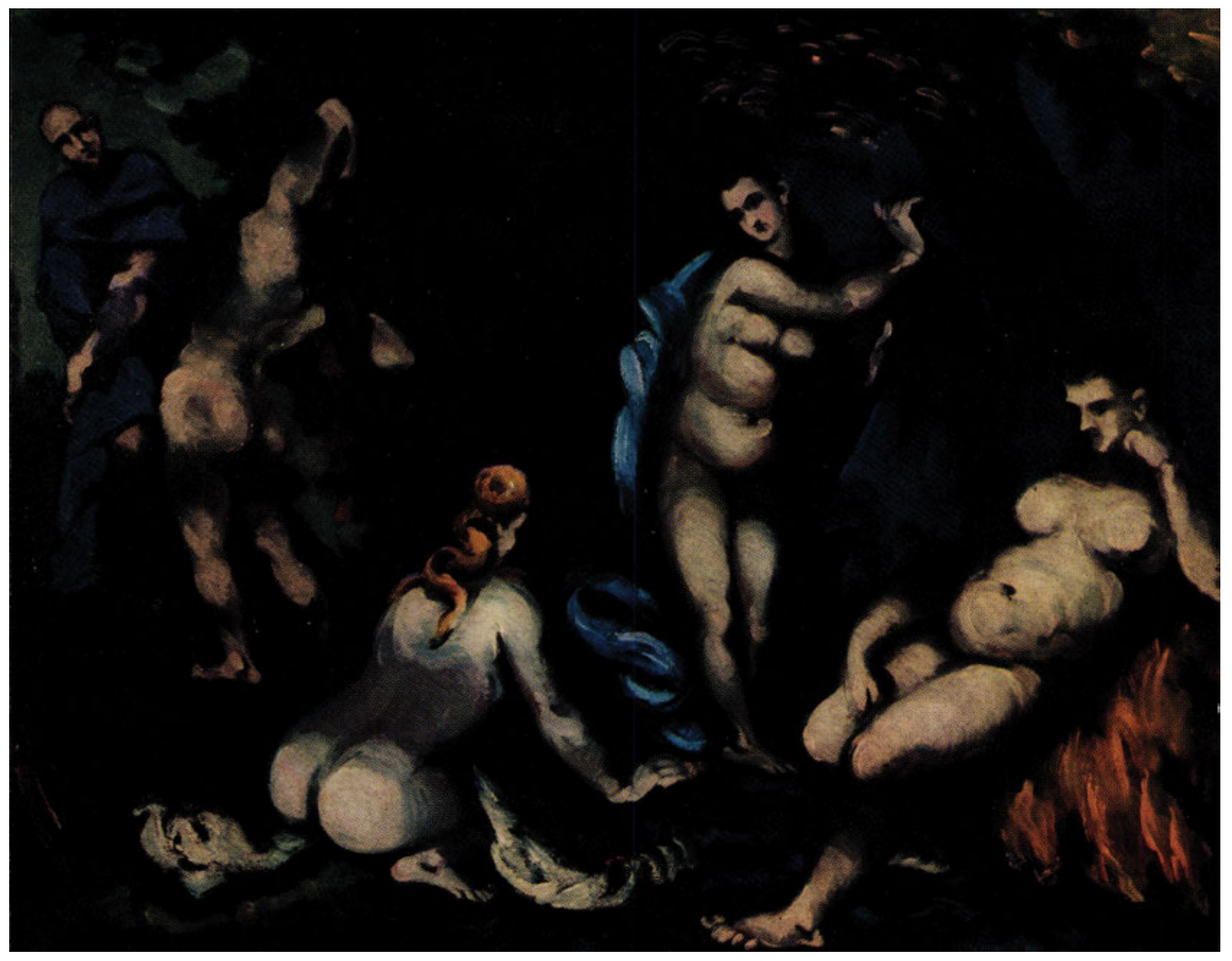

Paur. (ézanne, "I a Tentation de Saint Antoine," c. 1870)

(Courtesy, the Biihrle Collection)

Sec pages 129-130 


\title{
Zola before the
}

\section{Rougon-Macquart}

\author{
or \\ JOHN C. LAPP \\ or zo
}

University of Toronto Press 
Copyright, Canada, 1964, by

University of Toronto Press

Printed in Canada

Reprinted in 2018

ISBN 978-1-4875-7689-9 (paper) 